\title{
VASODILATOR THERAPY AFTER CARDIAC SURGERY: A REVIEW OF THE EFFICACY AND TOXICITY OF NITROGLYCERIN AND NITROPRUSSIDE
}

\author{
Joel A. Kaplan, Donald C. Finlayson and Scott Woodward
}

\section{ABSTRACT}

\begin{abstract}
Eight-five patients who required vasodilator therapy in the postoperative period after cardiac surgery were studied to compare the haemodynamic effects of nitroglycerin and nitroprusside, to evaluate local and systemic toxicity, and to develop long-range dosage recommendations. Ninety-one per cent of the patients received the vasodilators for postoperative hypertension. while nine per cent had low output syndromes. Both drugs significantly decreased blood pressure and central venous pressure, and increased heart rate. Nitroglycerin decreased both right and left ventricular filling pressures more than nitroprusside. No local toxicity or methaemoglobinaemia was found with either drug. Elevated thiocyanate levels were detected in 44 per cent of the nitroprusside group; however, none of the patients developed progressive metabolic acidosis. For prolonged infusions we found that nitroprusside at $1 \mu \mathrm{g} \cdot \mathrm{kg}^{-1} \cdot \mathrm{min}^{-1}$ and nitroglycerin at $0.5 \mu \mathrm{g} \cdot \mathrm{kg}^{-1} \cdot \mathrm{min}^{-1}$ were without significant toxicity.
\end{abstract}

AT THE PRESENT TIME vasodilators are commonly used after cardiac surgery in many institutions. The indications include (1) control of hypertension (a major problem leading to haemorrhage), increased myocardial oxygen demand and increased left ventricular work; and (2) reduction of left ventricular afterload in low output states. Intravenous nitroglycerin and sodium nitroprusside have been used to lower blood pressure during operation; ${ }^{1,2}$ to reduce myocardial oxygen demand in patients with ischaemic heart disease; ${ }^{3,4}$ to increase cardiac output in patients with heart failure; 5 and to reduce blood pressure for a short period of time after cardiac surgery. ${ }^{6}$ These studies have stressed the acute haemodynamic effects of the drugs, while none has evaluated toxicity or considered long-term dosage. Toxic doses of the nitrates are known to produce methaemoglobinaemia; ${ }^{7}$ and nitroprusside has been reported to produce cyanide and thiocyanate toxicity during rapid administration of large doses. ${ }^{8.9}$

The purposes of this study were (1) to compare the effects of nitroglycerin and nitroprusside on postoperative systemic haemodynamics; (2) to evaluate local and systemic toxicity; and (3) to develop long-term dosage recommendations.

Joel A. Kaplan, M.D., Professor of Anaesthesiology and Director, Division of Cardiothoracic Anaesthesia; Donald C. Finlayson, M.D., F.R.C.P.(C), Professor of Anaesthesiology; Scott Woodward, M.M.Sc., Physicians' Assistant in Anaesthesiology.

Division of Cardiothoracic Anaesthesia, Department of Anaesthesiology, Emory University School of Medicine, Atlanta, Georgia 30322.
TABLE 1

STUDY GROUPS

\begin{tabular}{lcc}
\hline \multicolumn{1}{c}{ Parameter } & NTG & SNP \\
\hline Patients & 60 & 25 \\
Age & 55.2 & 49.4 \\
Weight (kg) & 77.8 & 73.4 \\
Surgical procedure & & \\
$\quad$ CABG & 50 & 16 \\
Valve replacement & 6 & 7 \\
$\quad$ Others & 4 & 2 \\
Indication for vasodilator & & \\
$\quad$ Hypertension & 58 & 19 \\
$\quad$ Low cardiac output & 2 & 6 \\
\hline
\end{tabular}

\section{Material and Methods}

Eight-five patients who required vasodilator therapy in the postoperative period were studied in a prospective manner over a 12-month period (Table I). The choice of vasodilator was left to the attending anaesthetist. Intravenous nitroglycerin was prepared by our hospital pharmacy as previously reported.' Sixty patients received nitroglycerin and 25 patients nitroprusside. Of the nitroglycerin group 83 per cent had coronary artery surgery, and 10 per cent had valve replacement; while 64 per cent of the nitroprusside group had coronary revascularization, and 28 per cent had valve replacements. Ninety-one percent of the patients received the vasodilators for postoperative hypertension (systolic blood pressure greater than 20 per cent above preoperative levels); while nine per cent had low output syndromes. 
TABLE 11

VASOdLATOR REQuirements ( $\bar{x} \pm 1$ S.E.)

\begin{tabular}{lcc}
\hline & NTG & SNP \\
\hline Drug concentration $(\mu \mathrm{g} / \mathrm{ml})$ & $32-128$ & $100-400$ \\
Duration of therapy $(\mathrm{hrs})$ & $17.6 \pm 4.4$ & $39.4 \pm 10.5$ \\
Continued from O.R. & 28 & 13 \\
Begun in I.C.U. & 32 & 12 \\
Dosage requirement & & \\
$\quad$ Total dose $(\mathrm{mg})$ & $25.7 \pm 5.4$ & $143.1 \pm 34.8$ \\
Total dose/weight $\left(\mathrm{mg} \cdot \mathrm{kg}^{-1}\right)$ & $0.33 \pm .06$ & $1.95 \pm .08$ \\
$\quad$ Rate of administration $\left(\mu \mathrm{g} \cdot \mathrm{kg}^{-1} \cdot \mathrm{min}^{-1}\right)$ & $0.31 \pm .04$ & $0.83 \pm .05$ \\
Maximum dose & $224 \mathrm{mg} / 3$ hours & $760 \mathrm{mg} / 63$ hours \\
\hline
\end{tabular}

An anaesthetic technique consisting of morphine or fentanyl, nitrous oxide and enflurane or halothane was used for all patients and postoperative sedation and analgesia were continued with incremental doses of morphine. Postoperatively, patients were ventilated mechanically for at least 12 hours

The electrocardiogram, arterial blood pressure, central venous pressure and temperature were monitored continuously in all patients. Left atrial pressure catheters were present in 14 patients and 13 other patients had Swan-Ganz pulmonary artery catheters. Haemodynamic measurements were recorded at least every 15 minutes in all patients receiving vasodilator therapy. Measurements recorded just before the institution of vasodilator therapy were compared with those obtained when blood pressure was optimally controlled or when the maximum response to the vasodilator was obtained.

All patients had intermittent measurements of blood gases and electrolytes. Patients were examined daily for local toxic reactions at the site of vasodilator infusion. Methaemoglobin levels were measured by the Evelyn-Malloy spectrophotometric method, ${ }^{10}$ and thiocyanate levels by the Hill spectrophotometric technique." These measurements were made daily while the patients were receiving the vasodjlator, and until they returned to normal in those patients who had elevated values. Plasma cyanide levels were not measured, but plasma bicarbonate level was used as a measure of metabolic acidosis and possible cyanide toxicity.

Statistical analysis was done using student's paired $t$ test within each treatment group, and an unpaired $t$ test between treatment groups.

\section{Results}

Nitroglycerin was used in concentrations ranging from $32-128 \mu \mathrm{g} / \mathrm{ml}$, while nitroprusside was used in concentrations of $100-400 \mu \mathrm{g} / \mathrm{ml}$ (Table II). In the nitroglycerin group, 58 of the 60 patients required vasodilator therapy for the treatment of hypertension; and in the nitroprusside group, 19 of 25 . In about half the patients in each group therapy was commenced in the operating room and continued into the intensive care unit. The other half initially received the drugs postoperatively in the intensive care unit. The mean duration of therapy with nitroprusside was 39.4 hours, but was only 17.6 hours with nitroglycerin. More of the patients in the nitroprusside group were being treated for a low output syndrome which required a longer period of vasodilator therapy. With both drugs, additional antihypertensive therapy was needed in some patients, and consisted of varying combinations of chlorpromazine, phentolamine and alphamethyldopa. With this additional therapy, hypertension was controlled in all patients in the nitroprusside group. However, 13 patients on nitroglycerin therapy had to be switched to nitroprusside to provide adequate control of their blood pressure. Further treatment for patients with the low output syndrome consisted of dopamine in eight patients and the intraaortic balloon pump in four.

Patients in the nitroprusside group received a larger average total dose of drug, a larger total dose per kilogram of body weight, and a higher rate of administration of the vasodilator. These were all significantly different from the nitroglycerin group $(\mathrm{P}<.05)$. The maximum dose of drug used was $224 \mathrm{mg}$ of nitroglycerin over three hours and $760 \mathrm{mg}$ of nitroprusside over 63 hours. The maximum rate of administration was $128 \mu \mathrm{g} / \mathrm{min}$ of nitroglycerin and $200 \mu \mathrm{g} / \mathrm{min}$ of nitroprusside.

Haemodynamic changes were similar with both drugs (Figure 1). Nitroglycerin and nitroprusside significantly decreased blood pressure, 
TABLE III

TOXICITY OF VASODILATOR THERAPY

\begin{tabular}{|c|c|c|}
\hline & NTG & SNP \\
\hline Local reactions & None & None \\
\hline Methaemoblobin & 0 & 0 \\
\hline \multirow{2}{*}{\multicolumn{3}{|c|}{$\begin{array}{l}\text { Evelyn-Malloy assay } \\
\text { Normal }<0.1 \mathrm{~g} \%\end{array}$}} \\
\hline & & \\
\hline Thiocyanate & 0 & $11 / 25(44 \%)$ \\
\hline \multicolumn{3}{|l|}{ Hill assay } \\
\hline \multicolumn{3}{|l|}{ Normal non-smoker $<0.2 \mathrm{mg} \%$} \\
\hline $\mathrm{HCO}_{3}{ }^{-}$(mmol/1) & $23.3 \rightarrow 23.3$ & $24.4 \rightarrow 24.3$ \\
\hline
\end{tabular}

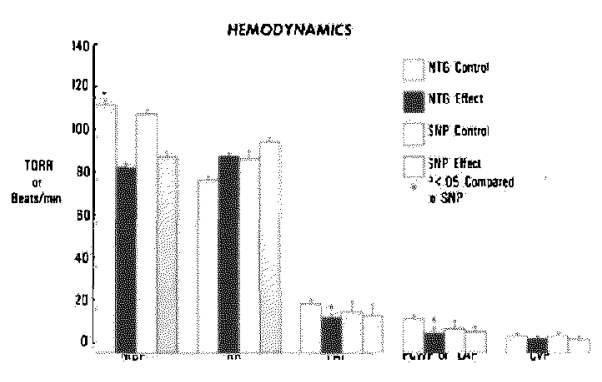

FIGURE I Haemodynamics are shown for both the nitroglycerin (NTG) and nitroprusside (SNP) groups. Mean values \pm 1 S.E. are demonstrated. Nitroglycerin lowered the pulmonary artery pressure and pulmonary capillary wedge pressure significantly more than nitroprusside $(\mathrm{P}<.05)$. MBP $=$ Mean Arterial Blood Pressure, $\mathrm{HR}=$ Heart Rate, $\mathrm{PAP}=$ Pulmonary Artery Pressure, PCWP = Pulmonary Capillary Wedge Pressure, $\mathrm{LAP}=$ Left Atrial Pressure, CVP = Central Venous Pressure.

reduced central venous pressure and increased heart rate $(P<, 05)$. Nitroglycerin decreased pulmonary artery and pulmonary capillary wedge pressures (left atrial pressure) more than nitroprusside $(\mathrm{P}<.05)$. With rewarming of the patients to normal body temperature in the immediate postoperative period, a decrease in the doses of both vasodilators was required.

There were no signs of local toxicity nor were methaemoglobin levels elevated in either treatment group (Table III). Thiocyanate levels were detectable in 11 patients in the nitroprusside group (44 per cent), and average $1.28,1.22$, and $1.83 \mathrm{mg}$ per cent on postoperative days, 1,2 , and 3 respectively. Only one paticnt who received $480 \mathrm{mg}$ of nitroprusside had elevated thiocyanate levels (up to $6 \mathrm{mg}$ per cent) on postoperative days 4-7. He showed symptoms of lethargy, nausea, and disorientation consistent with thiocyanate toxicity, but was in severe renal failure at the time and eventually died of heart failure. None of the patients receiving nitroprusside therapy developed progressive metabolic acidosis possibly indicative of cyanide poisoning. Table III shows the plasma bicarbonate level $\left(\mathrm{HCO}_{3}{ }^{-}\right)$at the beginning and upon completion of therapy with the vasodilator.

\section{Discussion}

Vasodilators are commonly used after cardiac surgery in many hospitals. The rationale for their use includes control of hypertension to reduce postoperative bleeding and left ventricular afterload. Stinson has previously shown that nitroglycerin and nitroprusside as well as chlorpromazine and trimethaphan can be used for the treatment of postoperative hypertension. ${ }^{6} \mathrm{Ni}$ troglycerin has been shown to act primarily by dilating the venous capacitance bed and, therefore, may not be as effective an antihypertensive agent as nitroprusside, which dilates both venous capacitance and arteriolar resistance vessels. ${ }^{12.13}$ In our nitroglycerin group, 13 patients (22 per cent) had to be switched to nitroprusside to adequately control hypertension. However, the maximum dose of nitroglycerin was only $128 \mu \mathrm{g} / \mathrm{min}$ during this study. Since this study was completed, Fahmy showed that larger doses of nitroglycerin can safely be used for deliberate hypotension. ${ }^{14}$ We now use larger doses of nitroglycerin (up to $400 \mu \mathrm{g} / \mathrm{min}$ ) in the intensive care unit to control hypertension. These larger doses would probably have avoided the need to switch to nitroprusside in some of the 13 patients. Another factor in ineffectiveness of nitroglycerin in some patients may have been that it was stored for eight hours and administered in plastic bags. Sturek has recently shown that nitroglycerin is absorbed by plastic, and after eight hours only 40 per cent of the original amount of nitroglycerin remained in the bag. Based on his studies, we 
now administer the nitroglycerin in glass bottles which have minimal absorption (less than five per cent loss in eight hours). ${ }^{15}$

Most of the patients in our study had undergone coronary artery revascularization surgery. In about half of the cases, the vasodilator had been begun in the operating room. Previous studies by Kaplan' and Lappas ${ }^{2}$ have shown that both nitroglycerin and nitroprusside can be used to control hypertension during operation. In a recent study, we compared the intra-operative use of nitroglycerin and nitroprusside. ${ }^{16}$ Both vasodilators were found to be effective in decreasing blood pressure, left and right ventricular filling pressures and myocardial oxygen demand. However, nitroprusside lowered the diastolic blood pressure and coronary perfusion pressure more than nitroglycerin. Nitroglycerin led to improvement of the ST-segments in 80 per cent of the patients, while nitroprusside led to improvement in 60 per cent of patients, and worsening of the ST-segments in 30 per cent. Studies by Chiariello, ${ }^{3}$ Mann, ${ }^{4}$ and Becker ${ }^{17}$ have shown that arteriolar vasodilators such as nitroprusside can lead to an intracoronary steal of blood from ischaemic areas of the heart and worsening of the electrocardiographic signs of ischaemia. Nitroglycerin, which primarily dilates the larger conductance vessels of the coronary circulation, has not been shown to cause this steal and actually increases blood flow to subendocardial ischaemic areas. Based on these studies, we prefer nitroglycerin to nitroprusside for the treatment of postoperative hypertension in patients with ischaemic heart disease, especially in those patients who were not totally revascularized.

Nitroprusside was used in 75 per cent of the patients with low output syndromes postoperatively. Previous studies have shown that it is more effective than nitroglycerin in this group of patients. ${ }^{18}$ Stinson showed that $77 \mu \mathrm{g} / \mathrm{min}$ of nitroprusside increased cardiac index by 19 per cent while decreasing systemic vascular resistance by 33 per cent and pulmonary vascular resistance by 26 per cent. In his study, nitroglycerin $(59 \mu \mathrm{g} / \mathrm{min})$ decreased cardiac index by $19 \mathrm{per}$ cent and produced no change in systemic or pulmonary vascular resistances. He recommended that the mean arterial blood pressure be decreased to $80-90$ torr $(10.6-12 \mathrm{kPa})$, while the left atrial pressure is maintained in the high normal range in order to maximize the increase in cardiac output. ${ }^{6,19}$

Nitroprusside is a relatively toxic drug compared to nitroglycerin. Nitroprusside has been shown to produce thiocyanate and cyanide toxicity, ${ }^{9}$ methaemoglobinaemia ${ }^{20}$ and acute phlebitis. ${ }^{21}$ Vesey has shown that a linear relationship exists between both plasma and red blood cell cyanide concentrations and the total dose of nitroprusside administered. ${ }^{9}$ Fatalities have been reported secondary to histotoxic hypoxia produced by cyanide poisoning. Based on these cases, the total recommended dosage of nitroprusside has been reduced to $1-$ $1.5 \mathrm{mg} \cdot \mathrm{kg}^{-1}{ }^{23}$ A recent study has shown that nitroprusside-induced cyanide toxicity can be prevented by simultaneous administration of hydroxocobalamin. ${ }^{24.26}$ Plasma thiocyanate concentrations have been shown to be an unreliable indicator of the extent of plasma cyanide levels. ${ }^{9}$ However, high levels of thiocyanate may produce their own toxic symptoms. ${ }^{25}$ Bower has also recently demonstrated that nitroprusside produced methaemoglobinaemia in one patient receiving a large dose of the drug (321 mg over 4 days). ${ }^{20}$ The patient developed cyanosis with an arterial oxygen tension of 95 torr $(12.6 \mathrm{kPa})$ and a methaemoglobin level of 16 per cent. Miller reported a patient who developed acute phlebitis at two different intravenous sites upon infusion of nitroprusside. ${ }^{21}$ In contrast, intravenous nitroglycerin as been found to be relatively free of toxicity. No local toxic reactions have been seen in any of the studies to date. Nitroglycerin (glyceryl trinitrate) is metabolized in the liver by an organic nitrate reductase to dinitrates and mononitrates which are excreted in the urine; and glycerol which is exhaled as carbon dioxide. 'There are no known toxic metabolic products. Methaemoglobinaemia can occur at very high doses of nitrates, but we have found none in this or our previous studies.

At the present time, for long-term therapy, we recommend maintaining the nitroprusside infusion rate less than $1 \mu \mathrm{g} \cdot \mathrm{kg}^{-1} \mathrm{~min}^{-1}$, and the total dose less than $1.5-2 \mathrm{mg} \cdot \mathrm{kg}^{-1 / 24}$ hours in patients with normal hepatic and renal function. At this dose range, we have seen minimal thiocyanate toxicity and no methaemoglobinaemia or metabolic acidosis. If larger doses are required, we prefer to switch to another vasodilator rather than to administer antagonists of cyanide, such as cyanocobalamin. For long-term administration, we have shown that nitroglycerin can be safely administered for days at rates up to $0.5 \mu \mathrm{g} \cdot \mathrm{kg}^{-1} \mathrm{~min}^{-1}$ (or $0.5 \mathrm{mg} \cdot \mathrm{kg}^{-1} / 24$ hours). In fact, it may be possible to administer both of these drugs at higher doses for longer periods of time. However, further studies of toxicity need to 
be done before this can be recommended, and extensive monitoring for toxic products (e.g., cyanide) would be needed.

In conclusion, both nitroglycerin and nitroprusside were shown to be effective in controlling postoperative hypertension in most of the patients. Decreasing doses of the vasodilators were required as the patients rewarmed in the postoperative period. Nitroglycerin was shown to reduce left ventricular filling pressure and central venous pressure more than nitroprusside. Nitroprusside led to elevations of thiocyanate levels in 44 percent of the patients, but none of the patients developed metabolic acidosis. No toxicity was found with nitroglycerin at the doses used. However, largerdoses of nitroglycerin need to be further evaluated for toxicity.

\section{REFERENCES}

1. Kaplan, J.A., Dunbar, R.W. \& Jones, E.L. Nitroglycenin infusion during coronary artery surgery. Anaesthesiology 45: 14, 1976.

2. Lappas, D.G., Loivenstein, E., Waller, J., et al. Hemodynamic effects of nitroprusside infusion during coronary artery operation in man. Circulation III - 3: 4, 1976.

3. Chiariello, M., Gold, H.K., Leinfach, R.C., et al. Comparison between the effects of nitroprusside and nitroglycerin on ischemic injury during acute myocardial infarction. Circulation 54: 766, 1976.

4. Mann, T., Cohn, P.F., Holman, L., et al Effect of nitroprusside on regional myocardial blood flow in coronary artery disease: Results in 25 patients and comparison with nitroglycerin. Circulation 57 : 732. 1978.

5. Chatterjee, K. \& Parmley, W.W. The role of vasodilator therapy in heart failure. Prog. Cardiovasc. Dis. 19: 301, 1977.

6. Stinson, E.B., Holloway, E.L., Derby, G., et al. Comparative hemodynamic responses to chlorpromazine, nitroprusside, nitroglycerin, and trimethaphan immediately after open-heart operation. Circulation $51,52-1: 26,1975$.

7. Needleman, P. Organic Nitrates. New York, Springer-Verlag, 1975.

8. Palmer, R.F., \& LAsseter, K.C. Sodium nitroprusside. N.E.J.M. 292: 294, 1975.

9. Vesey, C.J., COLE, P.V., \& Simpson, P.J. Cyanide and thiocyanate concentrations following sodium nitroprusside infusion in man. $\mathrm{Br}$. J. Anaesth. 48: 651, 1976.

10. Evelyn, K.A. \& Malloy, H.T. Microdetermination of oxyhemoglobin, methemoglobin, and sulfhemoglobin in a single sample of blood. J. Biol. Chem. 126: 655, 1938.
11. HILL, H.E. A contribution to the toxicology of sodium nitroprusside: 1. The decomposition and determination of sodium nitroprusside. Aust. Chem. Inst. J. \& Proc. 9: 89, 1942.

12. Mason, D.T. \& Braunwald. E. The effects of nitroglycerin and amyl nitrate on arteriolar and venous tone in the human forearm. Circulation 32 : $755,1965$.

13. Sнä, P.K. Ventricular unloading in the management of heart disease: Role of vasodilators. Am. Heart. J. 93: 256, 403, 1977.

14. Faнmy, N.R. Nitroglycerin as a hypotensive drug during general anesthesia. Anesthesiology 49: 17, 1978.

15. Sturek, J.K., Sokoloski, T.D., Winsley, W.T. et al. Stability of nitroglycerin injection determined by gas chromatography. Am. J. Hosp. Pharm. 35: $537,1978$.

16. Kaplan, J.A. \& Jones, E.L. Vasodilator therapy during coronary artery surgery: A comparison of nitroglycerin and nitroprusside. J. Thorac \& Cardiovasc. Surg. 77: 301-309, 1979.

17. BECKER, L.C. Conditions for vasodilator-induced coronary steal in experimental myocardial ischemia. Circulation 57: 1103, 1978.

18. Miller, R.R., Vismara, L.A., Williams, D.O., et al. Pharmacological mechanism for left ventricular unloading in clinical congestive heart failure: Differential effects of nitroprusside, phentolamine, and nitroglycerin on cardiac function and peripheral circulation. Circ. Res. 39: 127, 1976.

19. Stinson, E.B., Holloway, E.L., Deray. G.C. et al. Control of myocardial performance early after open-heart operations by vasodilator treatment. J. Thorac. \& Cardiovase. Surg. 73: 523, 1977.

20. Bower, P.J. \& Peterson, J.N. Methemoglobinemia after sodium nitroprusside therapy. N.E.J.M. 293: 865, 1975.

21. Miller, R. \& Stark, D.C. Acute phlebitis from nitroprusside. Anesthesiology 49: 372, 1978.

22. Davies, D.W., Kaslar, D., Steward, D.J., el al. A sudden death associated with the use of sodium nitroprusside for induction of hypotension during anesthesia. Canad. Anaesth. Soc. J. 22: 547, 1975.

23. McDowall, D.G., Keaney, N.P., Turner. J.M., et al. The toxicity of sodium nitroprusside. Br. J. Anaesth. 46: 327, 1974.

24. Cottrell, J.E., Casthely, P., Brodie, J.D., al al. Prevention of nitroprusside induced cyanide toxicity with hydroxocolalamin. N.E.J.M. 298: 809, 1978.

25. Tinker, J.H. \& Michenfelder, J.D. Sodium nitroprusside: Pharmacology, toxicology and therapeutics. Anesthesiology 45: 294, 1976.

26. TINKER, J.H. \& MiChENFELDER, J.D. Cardiac cyanide toxicity induced by nitroprusside in the dog: Potential for reversal. Anesthesiology 49: 109, 1978.

RÉSUMÉ

Quatre-vingt-cinq patients ayant requis des vasodilatateurs dans la période post-opératoire, après chirurgie cardiaque, ont fait l'objet d'une étude prospective dont les buts étaient de comparer les effects hémodynamiques de la nitroglycérine et du nitroprussiate de sodium, 
d'évaluer la toxicité locale et systémique de ces agents et d'établir des politiques sur leur usage. Leur emploi a été motivé par une hypertension artérielle post-opérátoire dans 91 pour cent des cas et par un syndrome de bas débit dans les autres cas. Les deux agents ont diminué (de façon significative) la pression artérielle et la pression veineuse avec une accélération de la fréquence cardiaque. La nitroglycérine diminuait les pressions de remplissage gauches et droites de façon plus marquée que le nitroprussiate. On n'a relevé aucune toxicité locale ou de méthémoglobinémie avec l'un ou l'autre agent. Des taux élevés de thiocyanate ont été relevés chez 44 pour cent des patients ayant reçu du nitroprussiate; cependant, aucun de ceux-ci n'a présenté d’acidose métabolique progressive. Nous avons trouvé que le nitroprussiate de sodium, à raison de $1 \mu \mathrm{g} \cdot \mathrm{kg}^{-1} \cdot \mathrm{min}^{-1}$ et la nitroglycćrinc, à raison de $0.5 \mu \mathrm{g} \cdot \mathrm{kg}^{-1} \cdot \mathrm{min}^{-1}$, ne présentaient pas de toxicité significative en administration prolongée. 